\title{
Degradabilidade in Situ da Matéria Seca e Proteína Bruta das Silagens de Seis Genótipos de Sorgo (Sorghum bicolor (L.) Moench) em Diferentes Estádios de Maturação
}

\section{Lívio Ribeiro Molina1, Lúcio Carlos Gonçalves ${ }^{1}$, Norberto Mário Rodriguez ${ }^{1}$, José Avelino Santos Rodrigues ${ }^{2}$, José Joaquim Ferreira ${ }^{3}$, Agenor Getúlio de Castro Neto ${ }^{1}$}

RESUMO - Com o objetivo de avaliar a degradabilidade in situ da matéria seca e proteína bruta das silagens de seis híbridos de sorgo em diferentes estádios de maturação, foram utilizados quatro novilhos mestiços de holandês-zebu, fistulados no rúmen, alimentados com feno de gramínea à vontade. As amostras de silagens foram secas e moídas em peneiras de $5 \mathrm{~mm}$, e $5 \mathrm{~g}$ das mesmas foram colocadas em sacos de náilon de 12 x $18 \mathrm{~cm}$ e tamanho de poros de $50 \mu \mathrm{m}$, que foram introduzidos nas fístulas dos bovinos. Após diferentes períodos de incubação $(6,12,24,48,72$ e 96 horas depois), os sacos de náilon foram removidos, as amostras de um mesmo híbrido, animal e período de incubação foram transformadas em um "pool” homogêneo, moído em peneira de $1 \mathrm{~mm}$ e armazenado para análises posteriores de MS e PB. O delineamento experimental utilizado foi o de parcelas sub-subdivididas no qual as parcelas eram as silagens dos diferentes híbridos, as sub-parcelas eram os estádios de maturação e as sub-sub-parcelas eram os seis períodos de incubação. Neste estudo, houve diferenças quanto ao desaparecimento de matéria seca e proteína bruta nas silagens de sorgo, embora as diferenças não possam ser atribuídas à porcentagem de grãos dos híbridos. O estádio de maturação das plantas influenciou a degradabilidade efetiva das frações digestíveis, favorecendo os cortes mais precoces.

Palavras-chave: degradabilidade $i n$ situ, matéria seca, proteína bruta, silagem, sorgo

\section{In Situ Degradability of Dry Matter and Crude Protein of Silages of Six Sorghum Genotipes in Different Stages of Maturation}

\begin{abstract}
In order to evaluate the in situ degradability of the dry matter and crude protein of silages of six sorghum genotipes in different stages of maturation, four fistulated crossbred holstein-zebu steers, fed with grass hay ad libitum, were utilized. The silage samples were dried and milled at $5 \mathrm{~mm}$ screen and $5 \mathrm{~g}$ of each sample were placed in $12 \mathrm{x} 18 \mathrm{~cm}$ naylon bags and $50 \mu \mathrm{m}$ porous size, and were introduced through the fistulas. After different times of incubation (6, 12, 24, 48, 72 and 96 hours later), the naylon bags were removed, the samples from the same genotipe, animal and time of incubation were transformed in a homogenous pool and milled at $1 \mathrm{~mm}$ screen, and were stored for further analysis of DM and CP. It was used the split-split plot design in which the parcels were the silages of different genotipes, split-plots were the periods of harvesting and split-split-plots were the six periods of incubation. In this study, there were differences on dry matter and crude protein disappearance of the sorghum silages, although these can not be attributed to the percentage of grains in the different genotipes. The age of the plant influenced the effective degradability of digestible fractions, benefiting early stages.
\end{abstract}

Key Words: crude protein, dry matter, in situ degradability, silage, sorghum

\section{Introdução}

A adaptação morfo-fisiológica do aparelho digestivo dos ruminantes permite o aproveitamento dos nutrientes das diferentes frações digestíveis presentes na diversidade de espécies vegetais, utilizadas por eles como alimento. Entretanto, para a correta utilização das alternativas alimentares disponíveis, é necessária a geração de conhecimentos sobre o valor nutritivo destas (Deschamps, 1994).

Como forma de avaliação de alimentos para ruminantes, a técnica do saco de náilon tem se apresentado como alternativa viável, principalmente em função de sua simplicidade e economicidade. A técnica consiste em colocar pequena quantidade de alimento em sacos de náilon porosos não degradáveis e suspendê-los no rúmen. Esta técnica, conhecida por degradabilidade in situ, tem sido adotada pelo AFRC (1992) como metodologia padrão para caracterização da degradabilidade ruminal do nitrogênio, pelo fato de fornecer as melhores comparações com os resultados in vivo. Embora a técnica tenha sido mais amplamente empregada para estudos de degradabilidade de proteína, a dinâmica ruminal de

\footnotetext{
${ }^{1}$ Escola de Veterinária da UFMG, C.P.: 567, CEP: 30123-970 Belo Horizonte-MG. E.mail: Imolina@vet.ufmg.br; agcneto@hotmail.com 
outros nutrientes pode também ser avaliada (Orskov \& McDonald, 1979).

Apesar do aumento da popularidade, a técnica também tem sido sujeita a uma avaliação intensa e críticas com relação a muitos fatores inerentes que influenciam a digestão, como tamanho da partícula, tamanho do poro do saco, quantidade de amostra e outros (Nocek, 1997).

Vários modelos têm sido propostos para descrever a digestão e a passagem de alimentos pelo trato digestivo do ruminante (Blaxter et al., 1956; Waldo et al., 1972; Baldwin et al., 1977; Mertens \& Ely, 1979; France et al. 1982; Baldwin et al. 1987; citado por Mertens, 1993). Nesses modelos, os resíduos de alimentos desaparecem do trato digestivo tanto por degradação e absorção ou por passagem para as fezes. A proporção de nutrientes consumidos que se torna disponível para os ruminantes é o resultado da competição entre digestão e passagem. A taxa e a extensão da digestão são variáveis críticas na descrição do processo digestivo. Esses parâmetros cinéticos são importantes porque eles não só descrevem a digestão, mas também caracterizam as propriedades intrínsecas dos alimentos que limitam sua disponibilidade aos ruminantes (Mertens, 1993). De acordo com Mehrez et al. (1977), os modelos semi-logarítmicos ou exponenciais são apropriados para o estudo da degradação das forrageiras. Orskov \& McDonald (1979) sugeriram um modelo exponencial para auxiliar no estudo da degradação de forrageiras no rúmen e uma equação baseada no princípio de redução do material durante a incubação, no estudo da degradação em função do tempo de incubação no rúmen.

McDonald (1981) sugeriu a existência de um uma fase anterior ao início do processo de degradação, onde a colonização microbiana teria começado, mas não a ponto de causar quebra no material incubado e denominou-o lag time ou lag phase, o qual poderia ser denominado tempo de colonização. Se o tempo de colonização não for considerado no modelo, a assíntota é superestimada e a taxa de degradação é subestimada (Stensing et al., 1994).

A mensuração da degradabilidade no rúmen, sem considerar a taxa de passagem, superestima a extensão da degradação em determinado horário, pois, em condições normais, partículas do alimento estão sujeitas à passagem para o compartimento seguinte antes de serem completamente degradadas (Orskov, 1982).

A técnica in situ tem sido comparada com diversos outros métodos de determinação do valor nutritivo dos alimentos. Madsen \& Hveplund (1985) compararam a degradabilidade da proteína in vivo, in vitro, a solubilidade em tampão e em sacos de náilon e concluíram que o método com relação mais estreita com o in vivo foi o dos sacos de náilon. A correlação mais próxima entre as degradabilidades in vivo e in situ, para vacas consumindo cerca de $14 \mathrm{~kg}$ de MS por dia, foi obtida a uma taxa de passagem de 0,08/hora. Estes autores encontraram ainda correlação linear $\left(\mathrm{R}^{2}=0,97\right)$ entre o conteúdo de N na MS e a degradabilidade da proteína para gramíneas e silagem de gramíneas.

O objetivo deste trabalho foi estudar a degradabilidade in situ da matéria seca e proteína bruta de silagens de seis híbridos de sorgo em três estádios de maturação.

\section{Material e Métodos}

O experimento com os animais foi conduzido nos estábulos do Hospital Veterinário da Escola de Veterinária da Universidade Federal de Minas Gerais (UFMG), em Belo Horizonte.

Para avaliação da degradabilidade in situ dos seis híbridos de sorgo foram utilizados quatro novilhos mestiços de holandês-zebu, fistulados no rúmen, com peso aproximado de $350 \mathrm{~kg}$ e idade entre 30 e 36 meses. Os animais receberam, previamente, uma dose de vermífugo. As cânulas eram inspecionadas diariamente e, quando necessário, os resíduos eram removidos com água. Além disso, semanalmente foi aplicado repelente ao redor das fístulas para evitar a instalação de larvas de moscas.

Os animais foram alojados em baias individuais, contidos por cabresto e com acesso livre à água e sal mineral. A limpeza das baias e dos comedouros era realizada diariamente juntamente com a inspeção dos bebedouros. A limpeza desses era feita quando necessário.

A dieta dos animais era composta por feno de tifton 85 à vontade (Tabela 1).

Os animais eram alimentados em duas refeições diárias, às 7 e $17 \mathrm{~h}$. A quantidade de feno era calculada para que houvesse em torno de $10 \%$ de sobras no cocho.

O feno para alimentação dos animais foi triturado em picadeira de forragens, em partículas de aproximadamente $5 \mathrm{~cm}$. Houve um período de 20 dias para adaptação dos animais à dieta, antes do início do experimento. 
Tabela 1 - Composição bromatológica do alimento fornecido Table 1 - Bromatological composition of feed

\begin{tabular}{lc}
\hline $\begin{array}{l}\text { Componentes } \\
\text { Components }^{1}\end{array}$ & $\begin{array}{c}\text { Feno de Tifton } \\
\text { Bermudagrass hay }\end{array}$ \\
\hline $\mathrm{MS}^{2}(\%)$ & 85,77 \\
$\mathrm{~PB}^{2}(\%)$ & 17,16 \\
$\mathrm{FDN}^{2}(\%)$ & 73,90 \\
$\mathrm{FDA}^{2}(\%)$ & 35,21 \\
Celulose $^{2}(\%)$ & 32,02 \\
Hemicelulose $^{2}(\%)$ & 38,69 \\
Lignina $^{2}(\%)$ & 3,19 \\
\hline
\end{tabular}

$2 \mathrm{MS}=$ matéria seca; $\mathrm{PB}$ = proteína bruta; $\mathrm{FDN}$ = fibra em detergente neutro; FDA = fibra em detergente ácido; celulose; hemicelulose; lignina. Dados expressos na matéria seca (\%).

$2 M S=$ dry matter; $P B=$ crude protein; $F D N=$ neutral detergent fiber; $F D A=$ acid detergentfiber; cellulose; hemicellulose; lignin. Data expressed in drymatter(\%).

Foram plantados 24 canteiros de sorgo medindo $7 \mathrm{~m}$ por $3,5 \mathrm{~m}$ cada, com espaçamento de $0,70 \mathrm{~m}$ entre linhas. O plantio foi realizado no dia 29 de novembro de 1995, com híbridos AG 2006, BR 601, BR 700, BRS 701, BR 303 e BR 304. O material foi colhido das duas linhas centrais, tirando-se 1 m nas bordaduras, em três estádios de maturação da panícula (dia 11/03/96: leitoso: corte 1, dia 18/03/96: pastoso: corte 2 e dia 03/04/96: farináceo: corte 3). A proporção de colmo, folhas e panículas dos híbridos utilizados, foram descritas por Molina et al. (2000).

O sorgo foi cortado manualmente, rente ao solo, sendo posteriormente picado em picadeira estacionária Nogueira, modelo DPM-4, e imediatamente ensilado. O material original foi analisado quanto ao teor de MS. Foram utilizados 72 silos de "PVC", com $10 \mathrm{~cm}$ de diâmetro e $40 \mathrm{~cm}$ de comprimento. A compactação foi feita com um pêndulo de ferro, e o fechamento com tampas de "PVC", dotadas de válvulas tipo "Bunsen". Os silos foram lacrados com fita crepe. Após a ensilagem, os silos foram transportados para o Laboratório de Nutrição Animal da Escola de Veterinária da Universidade Federal de Minas Gerais, onde foram mantidos até a abertura em temperatura ambiente.

Após a abertura do silo, seu conteúdo foi retirado e homogeneizado. Cada silagem foi amostrada, pesada e, dentro de bandejas aluminizadas, foram colocadas em estufa de ventilação forçada a $65^{\circ} \mathrm{C}$, por 72 horas. As amostras foram retiradas da estufa, deixadas por 24 horas em temperatura ambiente, e pesadas para a determinação da matéria pré-seca. As amos- tras pré-secas foram moídas em moinho estacionário "Thomas-Wiley", modelo 4, utilizando-se peneira de 1 milímetro (mm). Em seguida, foram guardadas em vidros com tampa para as análises de proteína bruta e matéria seca.

Os sacos utilizados foram confeccionados em náilon com poros de $50 \mu \mathrm{m}$ de diâmetro, nas dimensões de $15 \times 8 \mathrm{~cm}$. Eles foram secos a $65{ }^{0} \mathrm{C}$ por 24 horas e seus pesos registrados. Posteriormente, foram enchidos com $5 \mathrm{~g}$ da forrageira estudada, previamente moída a 5 milímetros (mm). Os sacos com amostras foram sorteados e atados por uma borracha elástica a um aro metálico que por sua vez prendia-se a uma presilha de contenção, que podia manter até seis aros, e consequentemente, seis saquinhos. Quatro presilhas estavam ligadas por uma corda de náilon ( $3 \mathrm{~mm}$ de diâmetro e $20 \mathrm{~cm}$ de comprimento) a um cilindro de ferro com 300 gramas de peso $(8 \times 3 \mathrm{~cm})$ que funcionava como âncora. $\mathrm{O}$ tamanho da corda de náilon que ligava a outra extremidade da âncora ao exterior era de $50 \mathrm{~cm}$. Cada animal continha os tratamentos sob o mesmo tempo de incubação, de modo que todos os sacos em um mesmo rúmen fossem retirados de uma só vez. Utilizaram-se quatro repetições de cada híbrido por animal, no mesmo horário.

Os tempos de incubação utilizados foram 6,12 , 24, 48, 72 e 96 horas. Imediatamente após serem retirados do rúmen, os sacos eram imersos em água fria e posteriormente lavados, manualmente, em água corrente em temperatura ambiente até que essa se mostrasse límpida. Após a lavagem, os sacos eram colocados em bandejas e levados à secagem em estufa de ventilação forçada por 48 horas, sendo então, transferidos para dessecador durante 30 minutos e pesados. Descontando-se o peso dos sacos vazios e limpos, determinou-se o desaparecimento da matéria seca no rúmen. Após este procedimento, o material restante nos sacos, de um mesmo híbrido, animal e período de incubação, foi transformado em um "pool” homogêneo, moído em peneira de $1 \mathrm{~mm}$ e armazenado em recipientes plásticos vedados, para análises posteriores.

Procedeu-se à determinação do tempo zero $\left(\mathrm{T}_{0}\right)$ a partir da colocação, nos sacos de náilon, de mesma quantidade de amostra utilizada para os demais horários de incubação, os quais foram fechados e lavados manualmente, em água de torneira durante vinte minutos. Foram, então, secos em estufa ventilada por 48 horas e pesados. Dessa forma, quantificou-se a 
fração solúvel de cada alimento. Empregaram-se três repetições por tratamento.

Os resíduos de incubação ruminal e do tempo zero foram moídos em peneira de $1 \mathrm{~mm}$. Procederam-se às análises de matéria seca em estufa a $105^{\circ} \mathrm{C}$ (AOAC, 1980) e proteína bruta (método Kjeldhal, de acordo com o AOAC, 1980).

O delineamento experimental utilizado foi o de parcelas sub-subdivididas. Para comparação das médias dos híbridos, dentro de cada estádio de maturação, dentro de cada período de incubação, e entre as médias dos diferentes tempos de incubação, para cada híbrido, utilizou-se o teste SNK ("Student Newman Keuls") $(\mathrm{p}<0,05)$.

As equações de regressão para o desaparecimento da MS e PB foram estimadas em microcomputador, por intermédio do programa SAEG 7.0, utilizando-se os procedimentos de Marquardt \& Regremd-1.

As equações de degradabilidade foram determinadas a partir do modelo proposto por Orskov \& McDonald (1979), com as adaptações propostas por Sampaio (1988), da seguinte forma:

$$
\mathrm{Dg}=\mathrm{A}-\mathrm{B} * \mathrm{e}^{-\mathrm{ct}} \quad(1)
$$

em que: A é a porcentagem máxima de degradação do material contido no saco de náilon; B é um parâmetro sem valor biológico de interesse. Se não houvesse tempo de colonização, ele corresponderia ao total a ser degradado pela ação dos microrganismos; c é a taxa fracional constante de degradação da fração que permanece no saco de náilon; $\mathbf{t}$ é o tempo de incubação no rúmen.

Após a determinação dos parâmetros A, B e c do modelo anterior, estimou-se o tempo de colonização, conforme McDonald (1981):

$$
\mathrm{TC}=-1-* \ln (\mathrm{A}-\mathrm{S}) \mathrm{c} \mathrm{B}
$$

A, B e c são os mesmos parâmetros definidos pela equação $\mathrm{Dg}=\mathrm{A}-\mathrm{B} *$ * e $\mathrm{e}^{-\mathrm{ct}}$, e $\mathrm{S}$ é a fração solúvel, determinada pela porcentagem de desaparecimento no tempo zero de incubação, sendo obtido pela simples imersão das amostras em água. Dessa forma, a parte da equação $\mathrm{A}$ - $\mathrm{S}$ equivale ao $\mathrm{b}$ da equação de Orskov \& McDonald (1979).

As degradabilidades efetivas (DE) foram calculadas segundo o modelo proposto por Orskov \& McDonald (1979):

$$
\begin{array}{r}
\mathrm{DE}=\mathrm{S}+\mathrm{b} * \mathrm{c} \\
\mathrm{C}+\mathrm{K}
\end{array}
$$

em que: $\mathbf{S}$ é a fração prontamente solúvel; b é um parâmetro sem valor biológico de interesse. Se não houvesse tempo de colonização, ele corresponderia ao total a ser degradado pela ação dos microrganismos; c é a taxa fracional constante de degradação da fração que permanece no saco de náilon; $\mathbf{k}$ é a taxa fracional de passagem de pequenas partículas, obtida após o uso de diferentes níveis de alimentação e diferentes dietas.

\section{Resultados e Discussão}

A composição bromatológica e o $\mathrm{pH}$ das silagens utilizadas para incubação ruminal são apresentados na Tabela 2.

Os parâmetros ruminais (nitrogênio amoniacal, pH e concentração de ácidos graxos voláteis) dos animais utilizados neste experimento foram avaliados assegurando plena capacidade de fermentação no ambiente ruminal dos animais experimentais.

A concentração média de nitrogênio amoniacal $\left(\mathrm{N}-\mathrm{NH}_{3} / \mathrm{NT}\right)$ e os valores de $\mathrm{pH}$ no líquido ruminal colhido 1 hora antes da alimentação e $0,5,1,3,5,7$, 9 e 11 horas após o fornecimento da refeição são apresentados na Tabela 3.

$\mathrm{O}$ pH médio observado foi de 6,6 e os valores mínimo e máximo foram 6,4 e 6,8 , respectivamente. Estes números são compatíveis com uma atividade celulolítica e proteolítica normal, não tendo afetado, portanto, a fermentação ruminal.

Van Houtert (1993) considera que valores de $\mathrm{pH}$ entre 6,5 e 7,0; são comuns em ruminantes alimentados com dietas volumosas. Hobson \& Stewart (1997) destacam que em valores de $\mathrm{pH}$ entre 6 e 7, torna-se possível a presença de todos os componentes de biomassa microbiana, sejam as bactérias, principalmente as celulolíticas, os protozoários e os fungos.

A concentração média de $\mathrm{N}-\mathrm{NH}_{3}$ observada foi de $15,41 \mathrm{mg} / 100 \mathrm{~mL}$. Esta concentração foi superior a $10 \mathrm{mg} / 100 \mathrm{~mL}$, considerado por Van Soest (1994), como mínima necessária para permitir adequada fermentação microbiana no rúmen. Dessa forma, podese supor que, estando o fornecimento de energia satisfeito, a qualquer momento estaria havendo quantidade suficiente de $\mathrm{N}_{-} \mathrm{NH}_{3} / \mathrm{NT}$ disponível para a microflora. Hobson \& Stewart (1997) destacam que em valores de $\mathrm{pH}$ entre 6 e 7, torna-se possível a presença de todos os componentes de biomassa microbiana, sejam as bactérias, principalmente as celulolíticas, os protozoários e os fungos.

Entretanto, estes valores estariam sempre aquém daqueles considerados ótimos $(23,5 \mathrm{mg} / 100 \mathrm{~mL})$ por Mehrez et al. (1977) em vacas de alta produção, para se atingir o máximo em fermentação microbiana. 
Tabela 2 - Composição bromatológica (\%MS) e pH das silagens de sorgo utilizadas para incubação ruminal, segundo o estado e a variedade

Table 2 - Bromatologic composition (\% DM) and $\mathrm{pH}$ of sorghum silages used for ruminal incubation, according to the time of harvesting and the variety

\begin{tabular}{|c|c|c|c|c|c|c|}
\hline \multirow[b]{2}{*}{$\begin{array}{l}\text { Componentes } \\
\text { Components }\end{array}$} & \multicolumn{6}{|c|}{$\begin{array}{c}\text { Estado leitoso } \\
\text { Milky stage }\end{array}$} \\
\hline & BR303 & BR304 & BR 601 & BR 700 & BRS 701 & AG2006 \\
\hline $\mathrm{MS}^{1}$ & $28,95^{\mathrm{ab}}$ & $32,05^{\mathrm{a}}$ & $20,80^{\mathrm{c}}$ & $27,56^{\mathrm{ab}}$ & $26,79^{\mathrm{b}}$ & $27,35^{\mathrm{ab}}$ \\
\hline $\mathrm{PB}^{2}$ & $7,57^{b}$ & $8,45^{\mathrm{a}}$ & $5,57^{\mathrm{d}}$ & $6,36^{\mathrm{c}}$ & $6,01^{\mathrm{cd}}$ & $6,66^{\mathrm{c}}$ \\
\hline $\mathrm{FDN}^{3}$ & $41,93^{a}$ & $38,65^{\mathrm{a}}$ & $54,51^{\mathrm{a}}$ & $51,85^{\mathrm{a}}$ & $52,91^{\mathrm{a}}$ & $50,42^{\mathrm{a}}$ \\
\hline $\mathrm{FDA}^{4}$ & $25,03^{\mathrm{a}}$ & $22,57^{\mathrm{a}}$ & $33,21^{\mathrm{a}}$ & $33,02^{\mathrm{a}}$ & $32,87^{\mathrm{a}}$ & $30,92^{\mathrm{a}}$ \\
\hline Celulose 5 & $19,85^{b}$ & $17,95^{\mathrm{b}}$ & $27,15^{\mathrm{a}}$ & $22,73^{\mathrm{ab}}$ & $26,51^{\mathrm{a}}$ & $18,45^{\mathrm{b}}$ \\
\hline Hemicelulose $^{6}$ & $16,89^{\mathrm{a}}$ & $16,08^{\mathrm{a}}$ & $21,31^{\mathrm{a}}$ & $18,83^{\mathrm{a}}$ & $20,03^{\mathrm{a}}$ & $19,51^{\mathrm{a}}$ \\
\hline Lignina $^{7}$ & $4,21^{\mathrm{a}}$ & $3,33^{\mathrm{a}}$ & $4,49^{a}$ & $3,65^{\mathrm{a}}$ & $5,03^{\mathrm{a}}$ & $6,73^{\mathrm{a}}$ \\
\hline $\mathrm{N}-\mathrm{NH}_{3}{ }^{8}$ & $8,16^{\mathrm{a}}$ & $8,75^{\mathrm{a}}$ & $11,08^{\mathrm{a}}$ & $10,38^{\mathrm{a}}$ & $11,21^{\mathrm{a}}$ & $10,49^{\mathrm{a}}$ \\
\hline \multirow[t]{2}{*}{$\mathrm{pH}^{9}$} & $3,8^{\mathrm{a}}$ & $3,6^{\mathrm{a}}$ & $3,8^{\mathrm{a}}$ & $3,8^{\mathrm{a}}$ & $3,8^{\mathrm{a}}$ & $3,8^{\mathrm{a}}$ \\
\hline & \multicolumn{6}{|c|}{$\begin{array}{c}\text { Estado pastoso } \\
\text { Pasty stage }\end{array}$} \\
\hline $\begin{array}{l}\text { Componentes } \\
\text { Components }\end{array}$ & BR303 & BR304 & BR 601 & BR 700 & BRS 701 & AG2006 \\
\hline $\mathrm{MS}^{1}$ & $35,52^{b}$ & $45,03^{\mathrm{a}}$ & $26,22^{c}$ & $39,32^{b}$ & $34,18^{\mathrm{b}}$ & 38,05 \\
\hline $\mathrm{PB}^{2}$ & $7,26^{\mathrm{a}}$ & $7,25^{\mathrm{a}}$ & $5,70^{\mathrm{b}}$ & $6,29^{\mathrm{b}}$ & $5,86^{\mathrm{b}}$ & $6,20^{\mathrm{b}}$ \\
\hline $\mathrm{FDN}^{3}$ & $46,75^{\mathrm{a}}$ & $35,11^{\mathrm{a}}$ & $48,67^{\mathrm{a}}$ & $48,89^{\mathrm{a}}$ & $49,37^{\mathrm{a}}$ & $44,55^{\mathrm{a}}$ \\
\hline $\mathrm{FDA}^{4}$ & $26,86^{\mathrm{a}}$ & $20,43^{\mathrm{a}}$ & $28,84^{\mathrm{a}}$ & $30,46^{\mathrm{a}}$ & $30,85^{\mathrm{a}}$ & $27,44 a$ \\
\hline Celulose $^{5}$ & $21,76^{\mathrm{a}}$ & $15,69^{\mathrm{b}}$ & $23,15^{\mathrm{a}}$ & $22,29^{\mathrm{a}}$ & $24,21^{\mathrm{a}}$ & $22,11^{\mathrm{a}}$ \\
\hline Hemicelulose $^{6}$ & $19,89^{\mathrm{a}}$ & $14,68^{\mathrm{a}}$ & $19,82^{\mathrm{a}}$ & $18,43^{\mathrm{a}}$ & $18,52^{\mathrm{a}}$ & $17,11^{\mathrm{a}}$ \\
\hline Lignina $^{7}$ & $3,98^{\mathrm{a}}$ & $3,45^{\mathrm{a}}$ & $4,55^{\mathrm{a}}$ & $4,64^{\mathrm{a}}$ & $4,36^{\mathrm{a}}$ & $4,22^{\mathrm{a}}$ \\
\hline $\mathrm{N}-\mathrm{NH}_{3}{ }^{8}$ & $10,35^{\mathrm{a}}$ & $10,69^{\mathrm{a}}$ & $11,31^{\mathrm{a}}$ & $10,58^{\mathrm{a}}$ & $10,31^{\mathrm{a}}$ & $9,19^{a}$ \\
\hline \multirow[t]{2}{*}{$\mathrm{pH}^{9}$} & $3,9^{\mathrm{a}}$ & $3,9^{\mathrm{a}}$ & $3,7^{b}$ & $3,9^{\mathrm{a}}$ & $3,8^{\mathrm{ab}}$ & $3,9^{\mathrm{a}}$ \\
\hline & \multicolumn{6}{|c|}{$\begin{array}{l}\text { Estado farináceo } \\
\text { Farinaceous stage }\end{array}$} \\
\hline $\begin{array}{l}\text { Componentes } \\
\text { Components }\end{array}$ & BR303 & BR304 & BR 601 & BR 700 & BRS 701 & AG2006 \\
\hline$\overline{\mathrm{MS}^{1}}$ & $38,89^{\mathrm{bc}}$ & $49,03^{\mathrm{a}}$ & $28,22^{\mathrm{c}}$ & $44,90^{\mathrm{ab}}$ & $33,40^{\mathrm{bc}}$ & $43,45^{\mathrm{ab}}$ \\
\hline $\mathrm{PB}^{2}$ & $7,05^{\mathrm{a}}$ & $7,54^{\mathrm{a}}$ & $5,71^{\mathrm{b}}$ & $5,88^{\mathrm{b}}$ & $5,90^{\mathrm{b}}$ & $5,82^{\mathrm{b}}$ \\
\hline $\mathrm{FDN}^{3}$ & $47,41^{\mathrm{a}}$ & $37,29^{\mathrm{a}}$ & $52,21^{\mathrm{a}}$ & $50,12^{\mathrm{a}}$ & $49,96^{\mathrm{a}}$ & $46,01^{\mathrm{a}}$ \\
\hline $\mathrm{FDA}^{4}$ & $26,78^{\mathrm{a}}$ & $21,61^{\mathrm{a}}$ & $31,03^{\mathrm{a}}$ & $31,64^{\mathrm{a}}$ & $30,52^{\mathrm{a}}$ & $28,14^{\mathrm{a}}$ \\
\hline Celulose ${ }^{5}$ & $22,25^{\mathrm{a}}$ & $16,78^{\mathrm{a}}$ & $25,66^{\mathrm{a}}$ & $22,12^{\mathrm{a}}$ & $24,59^{\mathrm{a}}$ & $22,74^{\mathrm{a}}$ \\
\hline Hemicelulose $^{6}$ & $20,62^{\mathrm{a}}$ & $15,67^{\mathrm{a}}$ & $21,17^{\mathrm{a}}$ & $18,48^{\mathrm{a}}$ & $19,44^{\mathrm{a}}$ & $17,87^{\mathrm{a}}$ \\
\hline Lignina $^{7}$ & $4,28^{\mathrm{a}}$ & $4,15^{\mathrm{a}}$ & $4,21^{\mathrm{a}}$ & $5,48^{\mathrm{a}}$ & $4,17^{\mathrm{a}}$ & $4,21^{\mathrm{a}}$ \\
\hline $\mathrm{N}-\mathrm{NH}_{3}{ }^{8}$ & $11,16^{\mathrm{a}}$ & $9,04^{\mathrm{a}}$ & $12,06^{\mathrm{a}}$ & $9,39^{\mathrm{a}}$ & $9,87^{\mathrm{a}}$ & $8,52^{\mathrm{a}}$ \\
\hline $\mathrm{pH}^{9}$ & $3,8^{\mathrm{a}}$ & $3,9^{\mathrm{a}}$ & $3,6 \mathrm{~b}$ & $3,9^{\mathrm{a}}$ & $3,7^{\mathrm{b}}$ & $3,9^{\mathrm{a}}$ \\
\hline
\end{tabular}

${ }^{1}$ Matéria seca; ${ }^{2}$ Proteína bruta; ${ }^{3}$ Fibra em detergente neutro; ${ }^{4}$ Fibra em detergente ácido; ${ }^{8}$ Nitrogênio amoniacal/nitrogênio total; 9 Potencial de hidrogênio;

Médias seguidas pela mesma letra minúscula não diferem em uma mesma linha (entre híbridos). Teste $S N K p<0,05$.

${ }^{1}$ Drymatter; ${ }^{2}$ Crude protein; ${ }^{3}$ Neutral detergent fiber; ${ }^{4}$ Acid detergent fiber; $;{ }^{5}$ Cellulose; ${ }^{6}$ Hemicellulose; ${ }^{7}$ Lignin; $;{ }^{8}$ Ammnonia nitrogen/total nitrogen; ${ }^{9} \mathrm{Hydrogen}$ potential; Means followed by the same small letter do not differ in the same row (among hybrids). SNK test $p<.05$.

Para que tal suposição seja dotada de maior confiabilidade, seria recomendada uma avaliação do crescimento microbiano, pelo fato deste ser influenciado também pela absorção de amônia pelo epitélio ruminal e também pela taxa de passagem para o abomaso (Hungate, 1966).
Neste estudo convencionou-se chamar de ácidos graxos voláteis (AGV) totais, o somatório dos ácidos acético, propiônico e butírico, uma vez que não se quantificaram os demais ácidos graxos de cadeia curta, normalmente presentes no líquido ruminal (isobutírico, 2-metil - butírico, valérico, isovalérico e 
Tabela 3 - Concentração média de nitrogênio amoniacal $\left(\mathrm{N}-\mathrm{NH}_{3}\right)$ e valores de $\mathrm{pH}$ no líquido ruminal colhido $-1,0,5,1,3,5,7,9$ e 11 horas após o fornecimento da refeição

Table 3 - Mean concentration of ammonia nitrogen $\left(\mathrm{N}_{-} \mathrm{NH}_{3}\right)$ and $\mathrm{pH}$ values in the ruminal juice collected $-1,0,5,1,3,5$, 7 and 11 hours after feeding

\begin{tabular}{|c|c|c|}
\hline $\begin{array}{l}\text { Tempo }(\mathrm{h}) \\
\text { Hours }\end{array}$ & $\mathrm{pH}$ & $\begin{array}{c}\mathrm{N}-\mathrm{NH}_{3}(\mathrm{mg} / 100 \mathrm{~mL}) \\
\mathrm{N}-\mathrm{NH}_{3}(\mathrm{mg} / 100 \mathrm{~mL})\end{array}$ \\
\hline $\begin{array}{l}\text { 1h antes da } \\
\text { alimentação }\end{array}$ & $6,6 \pm 0,30$ & $9,62 \pm 0,98$ \\
\hline $1 \mathrm{~h}$ before feeding & & \\
\hline 0,5 & $6,7 \pm 0,17$ & $16,23 \pm 5,72$ \\
\hline 1 & $6,7 \pm 0,10$ & $17,29 \pm 1,06$ \\
\hline 2 & $6,7 \pm 0,17$ & $20,06 \pm 3,09$ \\
\hline 3 & $6,8 \pm 0,13$ & $20,18 \pm 3,21$ \\
\hline 5 & $6,6 \pm 0,19$ & $15,19 \pm 2,97$ \\
\hline 7 & $6,5 \pm 0,40$ & $11,08 \pm 3,51$ \\
\hline 9 & $6,4 \pm 0,42$ & $9,26 \pm 3,93$ \\
\hline 11 & $6,6 \pm 0,13$ & $10,43 \pm 2,66$ \\
\hline Média ${ }^{1}$ & 6,6 & 15,41 \\
\hline
\end{tabular}

capróico). As concentrações dos AGV totais, acetato, propionato e butirato no líquido ruminal colhido 1 hora antes da alimentação e à $0,5,1,3,5,7,9$ e 11 horas após o fornecimento da refeição são apresentados na Tabela 4.

Os AGV totais elevaram-se de 1 hora antes da alimentação (jejum) até as 2 horas, quando tenderam a decrescer e retomar aos valores equivalentes ao tempo inicial. A relação acetato/propionato é típica de uma dieta rica em volumosos, de acordo com Dijkstra(1994).

Nos três cortes e em todos os tempos de incubação, o híbrido BR 304 apresentou maiores valores de desaparecimento da MS e os híbridos BR 700 e BRS 701 os menores valores, especialmente no corte 1 .

Os híbridos convergiram ao modelo exponencial proposto por Orskov \& McDonald (1979). As curvas de degradação demonstraram tendência de estabilização do processo fermentativo, sendo que o horário de $96 \mathrm{~h}$ foi suficiente para conseguir-se a máxima degradação das silagens. Os parâmetros de degradação ruminal da matéria seca dos diferentes híbridos de sorgo são mostrados na Tabela 5.

O AFRC (1992) considera as taxas de passagem de 2,5 e $8 \%$ por hora. A taxa de passagem de $2 \%$ por hora é adotada para bovinos e ovinos alimentados ao nível de mantença. A taxa de passagem de $5 \%$ por hora é utilizada para vacas com baixa produção, menor que $15 \mathrm{~kg}$ de leite por dia, bovinos de corte e ovinos alimentados à vontade com dietas mistas, enquanto a taxa de passagem de $8 \%$ por hora é utilizada para vacas de alta produção, maior que $15 \mathrm{~kg}$ de leite por dia e alimentadas com dietas mistas. A degradabilidade efetiva pode ser calculada assumindo-se valor para a taxa de passagem, ou estimandose a taxa de passagem de partículas pequenas (k). Com isso, o AFRC (1992) cita a degradabilidade efetiva para alguns alimentos utilizando os valores de taxas de passagem iguais a 2, 5 e $8 \%$ por hora.

As maiores degradabilidades efetivas foram encontradas nos híbridos BR 304 no corte $1(56,42$; $41,96$ e $35,33 \%)$ e AG 2006 no corte $2(56,18 ; 43,01$ e $37,02 \%$ ) para as taxas de passagem de 0,$02 ; 0,05$ e $0,08 / \mathrm{h}$, respectivamente. Observa-se que um híbrido de sorgo granífero apresentou DE da MS semelhante a um híbrido forrageiro. A menor DE foi encontrada no híbrido BRS 701 no corte 3 (46,62;32,63 e 27,08\%)

Tabela 4 - Concentração de AGV no conteúdo de rúmen (milimoles \%), em diferentes tempos em relação à refeição Table 4 - VFA concentration in the ruminal content (milimoles \%) in different times after meal

\begin{tabular}{lccccc}
\hline $\begin{array}{l}\text { Tempo }(\mathrm{H}) \\
\text { Hour }\end{array}$ & $\begin{array}{c}\text { Acetato } \\
\text { Acetate }\end{array}$ & $\begin{array}{c}\text { Propionato } \\
\text { Propionate }\end{array}$ & $\begin{array}{c}\text { Butirato } \\
\text { Butyrate }\end{array}$ & $\begin{array}{c}\text { AGV Totais } \\
\text { Total VFA }\end{array}$ & $\begin{array}{c}\text { Acet./Prop. } \\
\text { Acet./Prop. }\end{array}$ \\
\hline $\begin{array}{l}\text { 1h antes da alimentação } \\
\text { l h beforefeeding }\end{array}$ & 5,15 & 0,79 & 0,25 & 6,20 \\
0,5 & 5,78 & 0,86 & 0,32 & 6,97 \\
1 & 5,93 & 0,91 & 0,33 & 7,17 & 7,84 \\
2 & 6,31 & 1,11 & 0,43 & 7,03 & 6,71 \\
3 & 5,81 & 0,88 & 0,35 & 6,18 & 5,71 \\
5 & 4,94 & 0,86 & 0,38 & 5,72 & 5,77 \\
7 & 4,64 & 0,77 & 0,31 & 5,63 & 6,05 \\
9 & 4,58 & 0,75 & 0,30 & 6,13 & 6,53 \\
11 & 4,37 & 0,67 & 0,26 & & 5,30 \\
\hline
\end{tabular}

${ }_{1}$ CV Acetato1: 21,07 \%; Propionato2: 40,09 \%; Butirato3: 64,37\%.

${ }^{1}$ Acetate/Coefficient of variation; ${ }^{2}$ Propionate CV; ${ }^{3}$ Butyrate CV; 
Tabela 5 - Parâmetros de degradação ruminal da matéria seca dos híbridos de sorgo em diferentes cortes Table 5 - Ruminal degradation parameters of dry matter of sorghum hybrids in different times of harvesting

\begin{tabular}{|c|c|c|c|c|c|c|c|}
\hline $\begin{array}{l}\text { Híbrido } \\
\text { Hybrid }\end{array}$ & $\begin{array}{c}\text { Estado } \\
\text { Stage }\end{array}$ & $A(\%)^{5}$ & $\mathrm{~B}(\%)^{5}$ & $\mathrm{Kd}(\% / \mathrm{h})^{5}$ & $\begin{array}{c}\mathrm{TC}(\mathrm{h})^{5} \\
C T(h)^{1}\end{array}$ & $\mathrm{~S}(\%)^{5}$ & $\mathrm{R}^{2}(\%)^{5}$ \\
\hline BR303 & Leitoso $^{2}$ & 82,25 & 44,93 & 2,75 & 13,39 & 17,31 & 91,3 \\
\hline BR 303 & Pastoso $^{3}$ & 83,11 & 49,02 & 2,26 & 15,13 & 14,08 & 91,5 \\
\hline BR 303 & Farináceo 4 & 80,00 & 44,38 & 2,14 & 17,89 & 14,89 & 90,2 \\
\hline BR 304 & Leitoso $^{2}$ & 81,71 & 37,47 & 3,08 & 17,51 & 17,47 & 84,6 \\
\hline BR 304 & Pastoso $^{3}$ & 84,29 & 38,47 & 2,18 & 25,27 & 17,48 & 86,5 \\
\hline BR 304 & Farináceo 4 & 80,00 & 36,27 & 2,56 & 22,14 & 16,02 & 90,1 \\
\hline BR 601 & Leitoso $^{2}$ & 84,20 & 45,69 & 2,18 & 16,78 & 18,27 & 91,2 \\
\hline BR 601 & Pastoso $^{3}$ & 80,08 & 47,75 & 2,59 & 10,19 & 17,87 & 96,1 \\
\hline BR 601 & Farináceo $^{4}$ & 76,93 & 52,29 & 3,06 & 3,96 & 17,90 & 96,5 \\
\hline BR 700 & Leitoso $^{2}$ & 76,28 & 43,44 & 2,51 & 13,61 & 15,14 & 85,7 \\
\hline BR 700 & Pastoso ${ }^{3}$ & 74,64 & 44,76 & 3,59 & 8,63 & 13,61 & 90,4 \\
\hline BR 700 & Farináceo 4 & 75,38 & 44,66 & 2,96 & 12,02 & 11,61 & 86,1 \\
\hline BRS 701 & Leitoso $^{2}$ & 72,41 & 39,35 & 2,98 & 9,93 & 19,49 & 86,7 \\
\hline BRS 701 & Pastoso $^{3}$ & 71,29 & 42,23 & 3,17 & 7,47 & 17,72 & 88,9 \\
\hline BRS 701 & Farináceo $^{4}$ & 80,00 & 52,94 & 1,94 & 11,13 & 14,25 & 92,2 \\
\hline AG 2006 & Leitoso $^{2}$ & 78,93 & 44,78 & 2,77 & 8,01 & 23,01 & 90,3 \\
\hline AG 2006 & Pastoso ${ }^{3}$ & 79,54 & 45,76 & 3,01 & 8,16 & 21,02 & 89,4 \\
\hline AG 2006 & Farináceo $^{4}$ & 79,14 & 53,34 & 3,20 & 7,06 & 12,23 & 92,3 \\
\hline
\end{tabular}

1 Colonization time; ${ }^{2}$ Milky; ${ }^{3}$ Pasty; ${ }^{4}$ Farinaceous.

5 A é a porcentagem máxima de degradação do material contido no saco de náilon; B é um parâmetro sem valor biológico de interesse; c é a taxa fracional constante de degradação da fração que permanece no saco de náilon; t é o tempo de incubação no rúmen; S é a fração prontamente solúvel; $\mathbf{R}^{2}$ é a taxa de regressão.

${ }^{5} \boldsymbol{A}=$ total potential degradable fraction; $\boldsymbol{B}=$ undegradable fraction; $\boldsymbol{c}=$ fractional degradable rate; $\boldsymbol{t}=$ incubation time in the rumen; $\boldsymbol{S}=$ promptly soluble fraction; $\boldsymbol{R}^{2}=$ regression rate.

para as taxas de passagem de 0,$02 ; 0,05$ e $0,08 / \mathrm{h}$, respectivamente. É importante salientar que, com exceção dos híbridos BR 601 e BR 700, todos os outros apresentaram tendência de queda da DE com o aumento da maturidade.

Os resultados encontram-se na mesma faixa de variação obtida por Rabelo (1997) e Serafim (1998). Maiores DE foram assinaladas por Martins et al. (1998) em silagens de sorgo $(56,6 ; 46,0$ e 42,4\%) e de milho $(63,2 ; 54,8$ e $51,7 \%)$, para as taxas de passagem de 0,$02 ; 0,05$ e $0,08 / \mathrm{h}$, respectivamente.

Os híbridos apresentaram valores de $\mathrm{T}_{0}$ entre 15 e $23 \%$, a qual representa a porção de nitrogênio solúvel, ou amostra moída em partículas suficientemente pequenas para sair pelos poros do saco. Entretanto, dentro de um mesmo corte, os resultados foram muito próximos. Serafim (1988) obteve $13,86 \%$ de desaparecimento no $\mathrm{t}_{0}$ para sorgo forrageiro, 25,67\% para sorgo granífero e 38,14 de desaparecimento para sorgo de duplo propósito. Rabelo (1997) encontrou resultados de 35,27 e $38,86 \%$, ao avaliar silagens de sorgo com tanino e de porte médio. Para híbridos de sorgo de porte médio e sem tanino esse autor encontrou resultados de 46,93 e 48,10\%.
Os parâmetros de degradação ruminal da proteína bruta dos híbridos de sorgo em diferentes cortes são mostrados na Tabela 6 .

Todos os híbridos convergiram para o modelo exponencial para a degradação ruminal do nitrogênio. Os potenciais de degradação da proteína bruta encontrados nesse experimento são semelhantes aos obtidos por Serafim (1998): 78 a 95\% e bem superiores aos 37,3 obtidos por Martins et al. (1998) para silagens de sorgo. Para alguns híbridos, a taxa de degradação da fração lentamente degradável mostrou-se aquém do esperado, já que para Sampaio (1988) o parâmetro "c" da equação $\mathrm{Y}=\mathrm{A}-\mathrm{B} * \mathrm{EXP}{ }^{(-\mathrm{ct})}$, geralmente será de 2 a $6 \%$ para a maioria dos alimentos vegetais. Por outro lado, o híbrido BR 601 no corte 1 e AG 2006 no corte 2 superaram o valor superior do intervalo.

De acordo com Nocek (1985), a principal limitação associada com a técnica in situ é a incapacidade de caracterizar a disponibilidade do material solúvel e/ou filtrável que pode ser degradado em extensão maior ou menor em relação ao material digestível insolúvel. A validade da técnica depende da pressuposição de que a perda líquida de proteína dos sacos ocorre somente através da degradação (Broderick et al., 1988). 
Tabela 6 - Parâmetros de degradação ruminal da proteína bruta dos híbridos de sorgo em diferentes cortes Table 6 - Ruminal degradation parameters of crude protein of sorghum hybrids in different times of harvesting

\begin{tabular}{|c|c|c|c|c|c|c|}
\hline $\begin{array}{l}\text { Híbrido } \\
\text { Hybrid }\end{array}$ & $\begin{array}{c}\text { Estado } \\
\text { Stage }\end{array}$ & $A(\%)^{4}$ & $\mathrm{~B}(\%)^{4}$ & $\mathrm{C}(\% / \mathrm{h})^{4}$ & $\mathrm{~S}(\%)^{4}$ & $\mathrm{R}^{2}(\%)^{4}$ \\
\hline BR 303 & Leitoso $^{1}$ & 88,30 & 30,00 & 1,63 & 21,54 & 84,0 \\
\hline BR 303 & Pastoso $^{2}$ & 93,69 & 42,45 & 1,00 & 17,90 & 78,6 \\
\hline BR 303 & Farináceo ${ }^{3}$ & 80,00 & 32,17 & 1,50 & 18,17 & 71,9 \\
\hline BR 304 & Leitoso $^{1}$ & 90,00 & 30,00 & 1,66 & 22,28 & 67,3 \\
\hline BR 304 & Pastoso $^{2}$ & 87,41 & 33,10 & 1,45 & 20,96 & 69,7 \\
\hline BR 304 & Farináceo ${ }^{3}$ & 80,00 & 31,78 & 2,15 & 20,34 & 74,8 \\
\hline BR 601 & Leitoso $^{1}$ & 77,69 & 44,08 & 8,00 & 22,74 & 56,5 \\
\hline BR 601 & Pastoso $^{2}$ & 76,79 & 30,00 & 4,71 & 21,63 & 56,6 \\
\hline BR 601 & Farináceo ${ }^{3}$ & 80,00 & 36,55 & 2,03 & 22,33 & 81,3 \\
\hline BR 700 & Leitoso $^{1}$ & 76,11 & 32,48 & 3,11 & 19,55 & 82,0 \\
\hline BR 700 & Pastoso $^{2}$ & 75,54 & 36,10 & 3,82 & 17,18 & 73,6 \\
\hline BR 700 & Farináceo ${ }^{3}$ & 75,95 & 34,54 & 2,50 & 17,93 & 79,6 \\
\hline BRS 701 & Leitoso $^{1}$ & 76,33 & 40,23 & 4,01 & 22,83 & 72,6 \\
\hline BRS 701 & Pastoso $^{2}$ & 78,91 & 30,00 & 2,32 & 23,27 & 72,5 \\
\hline BRS 701 & Farináceo ${ }^{3}$ & 80,00 & 37,44 & 1,81 & 20,87 & 84,8 \\
\hline AG 2006 & Leitoso $^{1}$ & 90,00 & 30,00 & 1,32 & 23,01 & 79,1 \\
\hline AG2006 & Pastoso $^{2}$ & 79,40 & 30,00 & 8,00 & 21,02 & 80,2 \\
\hline AG 2006 & Farináceo $^{3}$ & 80,00 & 34,10 & 2,88 & 15,03 & 81,1 \\
\hline
\end{tabular}

${ }^{1}$ Milky; ${ }^{2}$ Pasty; ${ }^{3}$ Farinaceous;

${ }^{4}$ A é a porcentagem máxima de degradação do material contido no saco de náilon; B é um parâmetro sem valor biológico de interesse; $\mathbf{c}$ é a taxa fracional constante de degradação da fração que permanece no saco de náilon; $\mathbf{t}$ é o tempo de incubação no rúmen; $\mathbf{S}$ é a fração prontamente solúvel; $\mathbf{R}^{2}$ é a taxa de regressão.

${ }^{4} \boldsymbol{A}=$ total potential degradable fraction; $\boldsymbol{B}=$ =undegradable fraction; $\boldsymbol{c}=$ fractional degradable rate; $\boldsymbol{t}=$ incubation time in the rumen; $\boldsymbol{S}=$ promptly soluble fraction; $\boldsymbol{R}^{2}=$ regression rate.

O híbrido BR 303 no corte 2 apresentou o menor valor de degradabilidade efetiva da proteína bruta (43,16; 30,53 e 26,32\%). Os híbridos BR 601, BR 700 e BRS 701 apresentaram tendência de queda na DE da PB com o aumento da maturidade.

Valores superiores foram encontrados por Serafim (1998) para híbridos de porte baixo. O maior valor de DE foi encontrado para o híbrido AG 2006 (67,72;56,95 e 50,21\%) para taxas de passagem de 0,$02 ; 0,05$ e $0,08 / \mathrm{h}$ respectivamente. Valores inferiores foram encontrados por Serafim (1998) para sorgo forrageiro.

Martins et al. (1998) observaram números superiores aos desse trabalho, quando avaliaram silagem de milho $(73,2 ; 70,4$ e $68,8 \%)$ e de sorgo $(74,5 ; 67,9$ e 65,4\%). Secchiari et al. (1993) encontraram DE da PB em silagens de sorgo de 63,9; 47,7 e 43,7\% para as respectivas taxas de passagem. De acordo com Silva (1997), os grãos apresentam maiores digestibilidades que as folhas e colmos, o que resultaria em maior DE nos híbridos de porte baixo, o que não foi observado nesse trabalho.

\section{Conclusões}

Os indicadores de padrões de fermentação $(\mathrm{pH}$, $\mathrm{N}-\mathrm{NH}_{3} / \mathrm{NT}$ e teores de ácidos orgânicos) demonstram que as silagens em todos os tratamentos apresentaram bom padrão de fermentação final. De maneira geral, não houve alteração das frações fibrosas com o avanço do estádio de maturação. Considerando o intervalo de 25 a $35 \%$ de matéria seca como o indicado para a ensilagem de sorgo, todos os híbridos podem ser ensilados no estádio leitoso, exceto o BR 601, que deve ser ensilado no estádio de pastoso ou farináceo.

Neste estudo, houve diferenças quanto ao desaparecimento de matéria seca e proteína bruta nas silagens de sorgo. O estádio de maturação das plantas influenciou a degradabilidade efetiva das frações digestíveis, favorecendo os cortes mais precoces.

Os genótipos de sorgo não devem ser avaliados por parâmetros isolados, o que poderia conduzir a interpretações errôneas em casos específicos. 


\section{Literatura Citada}

AGRICULTURAL AND FOOD RESEARCH COUNCIL AFRC. 1992. Technical Committee on responses to nutrients: Nutritive requirementsof ruminant animal: protein. Nutrition Abstracts and Reservs, n.9, p.65-71, 1992.

ASSOCIATION OFFICIAL ANALYTICAL CHEMISTS AOAC. 1980. Official methods of analysis. 13.ed. Washington, D.C., 1980. 1015p.

BRODERICK, G.A.; WALLACE, R.J.; ORSKOV, E.R. et al. Comparision of estimates of ruminal protein degradation by "in vitro" and "in situ" methods. Journal of Animal Science, v.66, p.1739-1745, 1988.

DESCHAMPS, F.C. Degradabilidade ruminal da matéria seca e da proteína bruta de alguns alimentos utilizáveis na alimentação de ruminantes. Revista da Sociedade Brasileira de Zootecnia, v.23, n.6, p.898-908, 1994.

DIJKSTRA, J. Production and absortion of volatile fatty acids in the rumen. Livestock Production Science, v.39, n.1, p.61-69, 1994.

HOBSON, P.N.; STEWART, C.S. The rumen microbial ecosystem. London: Blackie Academic and Professional, 1997. 340p.

HUNGATE, R.E. The rumen and its microbes. London: Academic Press, 1966. 533p.

MADSEN, J.; HVELPLUND, T. Protein degradation in the rumen. A comparison between in vivo, nylon bag, in vitro, and buffer measurements. Acta Agriculturae Scandinavica Suplementum, v.25, p.103-124, 1985.

MARTINS, A.S.; ZEOULA, L.M.; PRADO, I.N. et al. Degradação ruminal da matéria seca e da proteína bruta de alguns alimentos. In: REUNIÃO ANUAL DA SOCIEDADE BRASILEIRA DE ZOOTECNIA, 35., 1998, Botucatu. Anais... Botucatu: Sociedade Brasileira de Zootecnia, 1998, RUM 063.

McDONALD, I. A revised model for the estimation of protein degradability in the rumen. Journal Agricultural Science, v.96, n.1, p.251-252, 1981.

MEHREZ, A.Z.; ORSKOV, E.R.; McDONALD, I. Rate of rumen fermentation in relation to ammonia concentration. British Journal of Nutrition, v.38, n.3, p.437-443, 1977.

MERTENS, D.R. Rate and extension of digestion. In: FORBES, J.M.; FRANCE, J. (Eds.). QUALITATIVE ASPECTS OF RUMINANT DIGESTION AND METABOLISM, 1993, Cambridge. [Proceedings...], Cambridge-UK: CAB International, 1993. p.13-51.

MOLINA, L.R.; GONÇALVES, L.C.; RODRIGUEZ, N.M. et al. Avaliação agronômica de seis híbridos de sorgo (Sorghum bicolor) (L.) Moench. Arquivo Brasileiro de Veterinária e Zootecnia, v.52, n.4, p.385-390, 2000.

NOCEK, J.E. Evaluation of specific variables affecting in situ estimates of ruminal dry matter and protein digestion. Journal of Animal Science, v.60, p.1347, 1985.

NOCEK, J.E. In situ and other methods to estimate ruminal protein and energy digestibility: a review. In: SIMPÓSIO INTERNACIONAL DE DIGESTIBILIDADE EM RUMINANTES, 1997, Lavras. Anais... Lavras: Universidade Federal de Lavras - FAEPE, 1997. p.197-239.
ORSKOV, E.R.; McDONALD, P. The estimation of protein degradability in the rumen from incubation measurements weighted according to rate of passage. Journal of Agricultural Science, v.92, n.2, 499-503, 1979.

ORSKOV, E.R. Protein nutrition in ruminants. London: Academic Press, 1982. 160p.

RABELO E. Degradabilidade in situ das silagens de híbridos de sorgo (Sorghum bicolor (L) Moench) de porte médio com diferentes teores de taninos e suculência no colmo. Belo Horizonte: Universidade Federal de Minas Gerais, 1997. 98p. (Mestrado em Zootecnia) - Universidade Federal de Minas Gerais, 1997.

SAMPAIO, I.B.M. Experimental designs and modelling techniques in the study of roughages degradation in rumen and growth of ruminants. Reading: University of Reading, 1988. 228p. Tese (Phd) - University of Reading, 1988.

SECCHIARI, P.; PISTOIA, A.; FERRUZZI, G. et al. Digeribilita in vivo e degradabilita in situ del sorgo integrale desidratato e pellettato. In: NATION CONGRESS, SCIENTIFIC ASSOCIATION OF ANIMAL PRODUCTION, 10, 1993, Bologna. Proceedings... Bologna: Associazione Scientifica di Produzione Animale, 1993. p.41-46.

SERAFIM, M.V. Degradabilidade in situ dos componentes nutricionais das silagens de três cultivares de sorgo (BR303, BR 601 e BR 700). Belo Horizonte: Universidade Federal de Minas Gerais, 1988. 87p. Dissertação (Mestrado em Zootecnia) - Universidade Federal de Minas Gerais, 1998.

SILVA, F.F. Qualidade de silagens de híbridos de sorgo (Sorghum bicolor (L) Moench) de portes baixo, médio e alto com diferentes proporções de colmo + folhas/panícula. Belo Horizonte: Universidade Federal de Minas Gerais, 1997. 94p. Dissertação (Mestrado em Zootecnia) - Universidade Federal de Minas Gerais, 1997.

STENSIG, T.; WEISBJERG, M.R.; HVELPLUND, T. Estimation of ruminal digestibility of NDF from sacco degradation and rumen fractional outflow rate. Acta Agriculturae Scandinavica, Sec. A, Animal Science, v.44, n.2, p.96-106, 1994.

Van HOUTERT, M.F.J. The production and metabolism of volatile fatty acids by ruminants fed roughages: A review. Animal Feed Science Technology, v.43, p.3/4, p.189-225. 1993.

Van SOEST, P.J. Nutritional ecology of the ruminant. 2.ed. Ithaca: Cornell University Press, 1994. 476p. 